\title{
Neonatal growth and breast cancer risk in adulthood
}

\author{
P Lagiou ${ }^{1,2,3}$, C-C Hsieh ${ }^{1,3,4}$, D Trichopoulos ${ }^{* 1,3}$, H-O Adami ${ }^{1,3}$, P Hall ${ }^{3}$, L Chie ${ }^{5}$ and A Ekbom ${ }^{6}$ \\ 'Department of Epidemiology, Harvard School of Public Health, 677 Huntington Avenue, Boston, MA 021 I 5, USA; '2Department of Hygiene, \\ Epidemiology and Medical Statistics, School of Medicine, University of Athens, 75 M Asias Street, Athens GR-I I 5 27, Greece; ${ }^{3}$ Department of Medical \\ Epidemiology and Biostatistics, Box 281 , Karolinska Institutet, Stockholm SE-17I 77, Sweden; ${ }^{4}$ Division of Biostatistics and Epidemiology, UMass Cancer \\ Center, University of Massachusetts Medical School, 364 Plantation Street, LRB 427, Worcester, MA 0I605,USA; ${ }^{5}$ Department of Obstetrics and \\ Gynecology, Beth Israel Deaconess Medical Center, 330 Brookline Avenue, Boston, MA 02215, USA; ${ }^{6}$ Clinical Epidemiology Unit, Department of \\ Medicine, Karolinska Institutet, Karolinska University Hospital, Stockholm SE-17I 76, Sweden
}

Birth size of a woman has been positively associated with her breast cancer risk, particularly before menopause, but no study has investigated neonatal growth in relation to this risk. We conducted a case-control study nested within a population-based cohort of women, born in Sweden between 1901 and 196I, covering all 405 breast cancer patients and 108I age- and hospital-matched controls, who were born after newborn charts became available. Compared to neonates who lost $<200 \mathrm{~g}$ after birth and grew at a rate $<25 \mathrm{~g} \mathrm{day}^{-1}$ after reaching postnatal weight nadir (ie, the minimum, before starting to regain weight), those who either lost $\geqslant 200 \mathrm{~g}$ after birth or grew $\geqslant 25 \mathrm{~g} \mathrm{day}^{-1}$ after nadir, or both, were at an approximately $50 \%$ increased breast cancer risk. The excess risk was striking and statistically significant among women below 50 years of age, but was not evident among older women. Immediate postnatal weight loss (an indicator of water loss, likely to reflect water retention associated with pregnancy hormones) as well as neonatal weight gain rate after the nadir (known to reflect growth hormone levels) was significantly positively associated with premenopausal breast cancer risk.

British Journal of Cancer (2008) 99, I544- 1548. doi:I0.1038/sj.bjc.6604702 www.bjcancer.com

Published online 30 September 2008

(C) 2008 Cancer Research UK

Keywords: breast cancer; postnatal growth; birth weight; early life; perinatal

There is much evidence that birth size of women influences their breast cancer risk (Michels and Xue, 2006; Park et al, 2008), particularly before menopause (World Cancer Research Fund/ American Institute for Cancer Research, 2007). No study, however, has investigated neonatal growth in relation to breast cancer risk, even though neonatal growth could be of particular importance, as it is strongly associated with neonatal IGF-1 levels (Albertsson-Wikland et al, 1998; Ogilvy-Stuart et al, 1998; Hikino et al, 2001; Skalkidou et al, 2003). IGF-1 levels, which could track through life, have been associated with breast cancer risk, particularly premenopausal breast cancer risk (Renehan et al, 2004; Fletcher et al, 2005; Rinaldi et al, 2006).

Evaluating neonatal growth is complicated because weight declines during the first few days after birth, mostly because of water loss, before starting to increase (Macdonald et al, 2003). The decline is likely to reflect the extent of water retention by the newborn at the time of delivery, under the influence of pregnancy hormones, including oestrogens (Stachenfeld and Keefe, 2002; Gomella et al, 2004; Stachenfeld and Taylor, 2004). The rate of weight gain after the nadir is influenced by growth factors, notably the IGF system and its determinants (Albertsson-Wikland

*Correspondence: Dr D Trichopoulos; E-mail: dtrichop@hsph.harvard. edu

Received 25 July 2008; revised 5 September 2008; accepted 10 September 2008; published online 30 September 2008 et al, 1998; Ogilvy-Stuart et al, 1998; Hikino et al, 2001; Skalkidou et al 2003).

We have investigated neonatal growth in relation to breast cancer in adult life by a case-control study nested within a population-based cohort of Swedish women.

\section{MATERIALS AND METHODS}

\section{Participants}

In Sweden, all residents have equal access to the governmental health-care system, and because there is essentially no private in-patient treatment, hospital services are population-based. Moreover, since 1 January 1947, all residents are assigned an individually unique nine digit national registration number, which contains information on the date of birth and the county in which the individual resided in 1947 or the county of birth for those born in 1947 or later. This number allows linkage with several Swedish registries, including the Swedish National Cancer Registry (Lunde et al, 1980).

In the mid-1990s, we studied the intrauterine environment in relation to breast cancer risk in the offspring using information from a cohort of women who had been born in one of the five participating hospitals in the Uppsala-Örebro Health Care Region from 1874 through 1961 and who had survived at least until 1 January 1958, when the Swedish National Cancer Registry was established (Ekbom et al, 1997). In that study, a total of 1068 cases 
were diagnosed until 1994 and 2727 controls were included (Ekbom et al, 1997).

For this study, we retrieved newborn charts with information on postnatal growth of neonates until their discharge. The maternity wards in the five hospitals started to use newborn charts at different calendar periods, and so newborn charts were available for 406 of the 1068 eligible case patients and for 1083 of the 2727 eligible controls, all born from 1901 onwards. Because extreme prematurity has been associated with breast cancer risk (Ekbom et al, 2000), we excluded babies born before 32 weeks of gestation (one case and two controls), leaving 405 cases and 1081 controls. Of the former, 90 were below the age of 40 years, 168 were aged 40-49 years, 119 were aged 50-59 years, whereas 28 were aged 60-68 years. The corresponding numbers among controls were $245,485,290$, and 61 women. In our sample, older women are underrepresented among cases because the National Cancer Registry began in 1958, when many older women belonged to cohorts born before the linked neonatal records became available. The ratio of controls to cases is lower among women 50 years of age or above at breast cancer diagnosis. Thus, among women below the age of 50 years, the control to case ratio is $2.8(730 / 258)$, whereas among older women it is $2.4(351 / 147)$. This is because in the earlier years, when older women were born, the likelihood of recording weight changes of newborns was much lower (when an index case was removed because of missing records, the corresponding controls were also removed, whereas if one or two controls had missing records, the remaining control(s) would suffice for retaining the corresponding case in the analysis).

At the birth of our subjects, breastfeeding predominated for newborns and the mother and child were usually discharged when the baby reached its birth weight. Generally, newborns lose weight during the first week and then gain weight (Macdonald et al, 2003). To examine whether these two different phases of postnatal pattern of growth were associated with subsequent risk of breast cancer, we determined maximum postnatal weight loss (defined as (birth weight) - (the lowest weight in the hospital)) and the rate of growth since the nadir (defined as (weight at discharge-weight at nadir)/ (day at discharge-day at nadir)).

On the basis of the literature (Macdonald et al, 2003) we have created the following five mutually exclusive categories: (a) neonates who remained at the maternity wards for more than 21 days without regaining their birth weight-these neonates were analysed separately because their weight loss and gain were unusual; (b) neonates with a maximum weight loss of $<200 \mathrm{~g}$ and growth rate after nadir $<25 \mathrm{~g} \mathrm{day}^{-1}$; (c) neonates with a maximum weight loss of $\geqslant 200 \mathrm{~g}$ and growth rate after nadir $<25 \mathrm{~g} \mathrm{day}^{-1}$; (d) neonates with a maximum weight loss of $<200 \mathrm{~g}$ and growth rate after nadir $\geqslant 25 \mathrm{gday}^{-1}$ and (e) neonates with a maximum postnatal weight loss of $\geqslant 200 \mathrm{~g}$ and growth rate after nadir $\geqslant 25 \mathrm{~g} \mathrm{day}^{-1}$. All neonates in categories $\mathrm{b}-\mathrm{e}$ remained at the maternity wards for a maximum of 21 days. The weight loss cutoff of $200 \mathrm{~g}$ was a round figure derived from the $6.6 \%$ reported to be the median percent of birth weight loss for breastfed children (Macdonald et al, 2003), and so with birth weight around $3000 \mathrm{~g}$, we have $3000 \mathrm{~g}^{\star} 0.066 \simeq 200 \mathrm{~g}$. The cutoff for the daily rate of growth after nadir was rounded at $25 \mathrm{~g} \mathrm{day}^{-1}$, as the reported median time for birth weight recovery among breastfed children is 8.3 days (Macdonald et al, 2003), so that $200 \mathrm{~g}$ divided by 8.3 days equals approximately $25 \mathrm{~g} \mathrm{day}^{-1}$.

\section{Statistical analyses}

The statistical analyses were undertaken by modelling the data through conditional logistic regression using PROC PHREG of the SAS statistical software (version 9, SAS Institute, Cary, NC, USA). Covariates adjusted in the analysis included maternal age (in years as a continuous variable), maternal socioeconomic status (low, medium, and high as an ordinal variable), maternal parity
(1, 2, and $\geqslant 3$ as categorical indicator variables), pregnancy toxaemia (yes/no), neonatal jaundice (yes/no), twin membership (singleton, monozygotic, and dizygotic as categorical indicator variables), and birth weight (<2500, 2500-2999, 3000-3499, $3500-3999$, and $\geqslant 4000 \mathrm{~g}$ as categorical indicator variables).

The study was approved by the Institutional Review Boards of the Karolinska Institutet, Sweden, the Harvard School of Public Health, USA, and the US Department of Defense.

\section{RESULTS}

Table 1 presents the maternal and perinatal characteristics of breast cancer patients and their control women (matched to the cases with variable matching ratio). As reported earlier (Ekbom et al, 1997), neonatal jaundice is more common among cases, whereas maternal toxaemia is more common among controls. In this data set, the association between birth size and breast cancer risk was weak and statistically non-significant (Ekbom et al, 1997). Spearman's correlation coefficients of birth weight with maximum weight loss and daily weight gain since nadir were 0.48 $(P<0.0001)$ and $0.02(P=0.55)$, respectively. In these bivariate and possibly confounded patterns, neonatal weight loss appears more pronounced among cases than among controls. There is also some evidence that weight gain after nadir is more pronounced among breast cancer patients below the age of 50 years compared with controls.

After controlling for confounding through conditional logistic regression, we found no evidence that neonates who did not conform to the usual growth pattern are at different breast cancer risk when compared with the reference category of neonates who lost less than $200 \mathrm{~g}$ after birth and grew at a rate less than $25 \mathrm{~g} \mathrm{day}^{-1}$ after nadir (Table 2). In contrast, however, neonates who lost $\geqslant 200 \mathrm{~g}$ after birth, or neonates who grew at a rate of $\geqslant 25 \mathrm{~g} \mathrm{day}^{-1}$ after nadir, or neonates with both of these growth pattern characteristics were at an approximately $50 \%$ increased risk in later life when compared with the reference category. The excess risk was evident and statistically significant exclusively among women below the age of 50 years, who were presumably premenopausal at breast cancer diagnosis. As, in our data, women were designated as pre- or postmenopausal relying only on their age, we have evaluated whether there is an interaction between age and growth pattern with respect to breast cancer risk, and the results were of borderline significance $(P \sim 0.06)$.

\section{DISCUSSION}

In our case-control study, nested within a well-defined population-based cohort of Swedish women, we have found evidence that immediate postnatal weight loss of the newborn, as well as the neonate's weight gain rate after reaching a nadir of postnatal weight, are significantly positively associated with breast cancer risk among women below the age of 50 years. As indicated in the Introduction, in the light of the literature, we considered the immediate postnatal weight loss as an indicator of water loss, probably reflecting water retention caused by pregnancy hormones, and the postnadir rate of growth as an indicator of higher levels of growth hormones, particularly IGF-1.

We interpret our findings as indicating that higher levels of pregnancy hormones and growth hormones during the immediate postnatal period, particularly IGF-1, play an important role in premenopausal breast cancer risk several decades later.

No association of postnatal growth pattern with breast cancer risk was evident among women 50 years of age or above, and presumably postmenopausal who, however, were relatively few in this study sample. Besides the numbers, it is also possible that any effect of perinatal factors on risk is gradually diluted as additional adult life breast cancer risk factors are introduced, in line with the 
Table I Maternal and perinatal characteristics of 405 breast cancer cases and 1081 matched control subjects

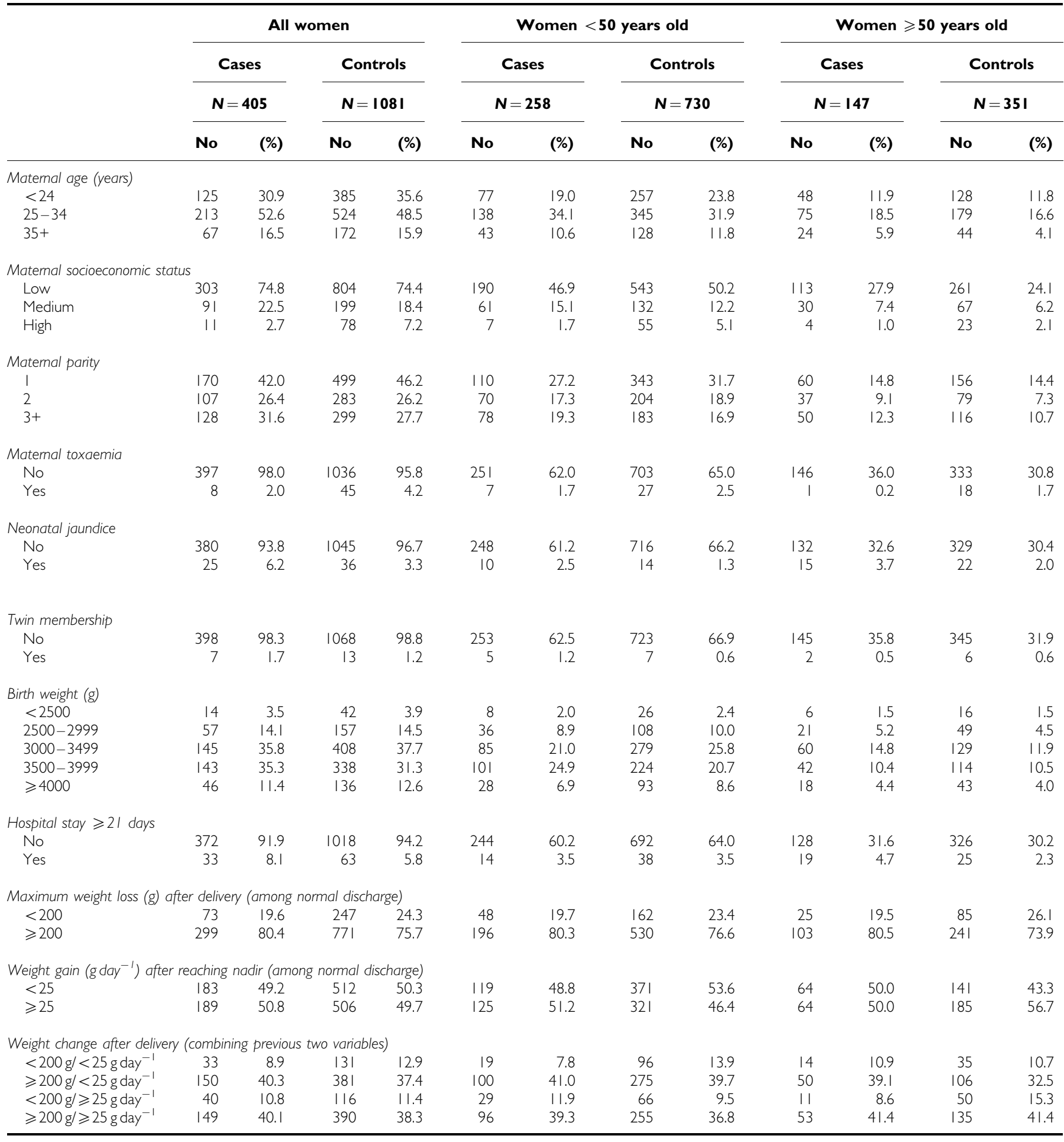

conclusion of a major review that birth weight is positively associated with breast cancer risk mostly among premenopausal women (World Cancer Research Fund/American Institute for Cancer Research, 2007). Age at and type of menopause (natural or induced) are important postmenopausal risk factors, and pre- and postmenopausal breast cancer are frequently treated as distinct entities in studies focusing on their hormonal and non-hormonal aetiology (Hankinson et al, 2008).
Our study makes use of the unusual opportunities available in Sweden for linking population-based databases and registries. The nested case-control study design retains the advantages of a cohort study in terms of minimisation of information and selection bias. Exclusions were simply on the basis of the availability of linked newborn charts. The sample contained many more women below the age of 50 years (presumably premenopausal) than older women (presumably postmenopausal), and 
Table 2 Conditional logistic regression-derived ${ }^{\mathrm{a}}$ odds ratios (ORs) and 95\% confidence intervals (Cls) for breast cancer in relation to the patterns of postnatal weight change

\begin{tabular}{|c|c|c|c|c|c|c|c|c|c|}
\hline & \multicolumn{3}{|c|}{ All women } & \multicolumn{3}{|c|}{$\begin{array}{c}\text { Women }<50 \text { years old } \\
\text { (presumably premenopausal) }\end{array}$} & \multicolumn{3}{|c|}{$\begin{array}{c}\text { Women } \geqslant 50 \text { years old } \\
\text { (presumably postmenopausal) }\end{array}$} \\
\hline & OR & $95 \% \mathrm{Cl}$ & $P$-value & OR & $95 \% \mathrm{Cl}$ & $P$-value & OR & $95 \% \mathrm{Cl}$ & $P$-value \\
\hline \multicolumn{10}{|l|}{$\begin{array}{l}\text { Maximum weight loss/ } \\
\text { daily weight gain since nadir }\end{array}$} \\
\hline$\geqslant 200 \mathrm{~g} /<25 \mathrm{~g} \mathrm{day}^{-1}$ & 1.53 & $0.96-2.44$ & 0.08 & 1.81 & $1.00-3.25$ & 0.048 & 0.95 & $0.41-2.19$ & 0.90 \\
\hline Irregulars (hospitalised for $>21$ days) & 1.37 & $0.64-2.90$ & 0.42 & 1.09 & $0.40-2.95$ & 0.87 & 1.35 & $0.39-4.67$ & 0.64 \\
\hline
\end{tabular}

${ }^{a}$ Controlling for maternal age, maternal socioeconomic status, maternal parity, pregnancy toxaemia, neonatal jaundice, twin membership, and birth weight.

so there should be more confidence in the associations found among the former than on their absence among presumably postmenopausal women. In the base of the study, on which we relied, birth size indicators (birth weight, birth length, and placental weight) were very weakly positively related to risk, although mutual adjustment of these indicators tended to increase the positive trends (Ekbom et al, 1997). However, when a true but weak association is investigated in many studies, some are bound to generate non-significant or even null results (Michels and Xue, 2006; Park et al, 2008). We had no information about adult life risk factors for breast cancer (e.g., age at menarche), but even if associations of such factors with postnatal growth were to be found, they would probably have been placed as intermediates (which should not be controlled for) rather than as confounders (which should). There are, of course, several other risk factors (e.g., age at the first pregnancy, parity, hormone replacement therapy, and so on), which could not act as confounders, as they are unlikely to be related to postnatal growth.

It has been postulated that the likelihood of breast cancer depends on the number of mammary stem cells, which is determined in early, including intrauterine life, as well as on the early postnatal levels of growth-enhancing mammotropic hormones, which affect the replication rate of such stem cells (Trichopoulos, 1990; Adami et al, 1995; Trichopoulos et al, 2005, 2008). Birth size is known to influence breast cancer risk (Michels and Xue, 2006; Park et al, 2008), and there is compelling evidence that periadolescent growth (Ahlgren et al, 2004) and adult height (Tretli 1989; World Cancer Research Fund/American Institute for Cancer Research, 2007) are also associated with this risk. Using haematopoietic stem cells as probable correlates of the difficult-to-measure mammary stem cells, the size of their pool was positively associated with both umbilical cord growth hormones and birth weight (Savarese et al, 2007; Strohsnitter et al, 2008). No earlier investigation, however, has examined postnatal growth in relation to breast cancer risk, even though postnatal growth is rapid and the mammary gland is far from being fully differentiated (Russo and Russo, 1987).
The IGF system is associated with both breast cancer risk (Renehan et al, 2004; Fletcher et al, 2005; Rinaldi et al, 2006) and postnadir growth (Albertsson-Wikland et al, 1998; OgilvyStuart et al, 1998; Hikino et al, 2001; Skalkidou et al, 2003), and could therefore plausibly explain the association of postnadir growth with this risk. Our explanation of the association of immediate postnatal weight reduction with breast cancer risk invokes higher levels of pregnancy hormones, including oestrogens, on the basis of well-known properties of these hormones (Stachenfeld and Keefe, 2002; Gomella et al, 2004; Stachenfeld and Taylor, 2004).

Replication of our results is clearly necessary. The examination of the possible differential association of neonatal growth with hormone-sensitive and hormone-insensitive breast cancer, as reflected for instance in hormone receptor expression (Duffy, 2006; Hankinson et al, 2008), would also be of importance. Such information was not available in our database. Animal models have provided valuable information with respect to early life exposures and breast cancer risk (Hilakivi-Clarke et al, 1994; Hilakivi-Clarke and de Assis, 2006) and could be useful in relation to postnatal growth.

The findings of this study are intriguing and the apparent magnitude of effect (the twofold increases in premenopausal breast cancer risk for essentially dichotomous contrasts) indicates that the phenomenon is of considerable importance. Confidence limits, however, are wide and the absence of evidence for even additive interaction is of some concern.

\section{ACKNOWLEDGEMENTS}

The study was funded by the W81XWH-05-1-0314 Innovator Award, US Department of Defense Breast Cancer Research Program, and the Office of the Congressionally Directed Medical Research Programs.

\section{REFERENCES}

Adami H-O, Persson I, Ekbom A, Wolk A, Pontén J, Trichopoulos D (1995) The aetiology and pathogenesis of human breast cancer. Mutat Res 333: $29-35$

Ahlgren M, Melbye M, Wohlfahrt J, Sørensen TI (2004) Growth patterns and the risk of breast cancer in women. $N$ Engl J Med 351: 1619-1626

Albertsson-Wikland K, Boguszewski M, Karlberg J (1998) Children born small-for-gestational age: postnatal growth and hormonal status. Horm Res 49(Suppl 2): 7-13

Duffy MJ (2006) Estrogen receptors: role in breast cancer. Crit Rev Clin Lab Sci 43: $325-347$

Ekbom A, Erlandsson G, Hsieh C-C, Trichopoulos D, Adami H-O, Cnattingius S (2000) Risk of breast cancer in prematurely born women. $J$ Natl Cancer Inst 92: 840-841

Ekbom A, Hsieh C-C, Lipworth L, Adami H-O, Trichopoulos D (1997) Intrauterine environment and breast cancer risk in women. J Natl Cancer Inst 88: $71-76$

Fletcher O, Gibson L, Johnson N, Altmann DR, Holly JM, Ashworth A, Peto J, Silva IS (2005) Polymorphisms and circulating levels in the insulin-like growth factor system and risk of breast cancer: a systematic review. Cancer Epidemiol Biomarkers Prev 14: 2-19 
Gomella TL, Cunningham MD, Eyal FG, Zenk KE (eds) (2004) Neonatology: management, procedures, on-call problems, diseases, and drugs. Nutritional Management, 5th edn. Chapter 8, p 77. New York, NY: McGraw-Hill

Hankinson S, Tamimi R, Hunter D (2008) Breast cancer. In Textbook of Cancer Epidemiology, Adami HO, Hunter D, Trichopoulos D (eds) 2nd edn, pp 403-445. New York, NY: Oxford University Press

Hikino S, Ihara K, Yamamoto J, Takahata Y, Nakayama H, Kinukawa N, Narazaki Y, Hara T (2001) Physical growth and retinopathy in preterm infants: involvement of IGF-I and GH. Pediatr Res 50: $732-736$

Hilakivi-Clarke L, Clarke R, Lippman ME (1994) Perinatal factors increase breast cancer risk. Breast Cancer Res Treat 31: 273-284

Hilakivi-Clarke L, de Assis S (2006) Fetal origins of breast cancer. Trends Endocrinol Metab 17: $340-348$

Lunde As, Lundeborg S, Lettenstrom GS, Thuesen L, Huebner J (1980) The Person-Number Systems of Sweden, Norway, Denmark and Israel. Hyattsville (MD): National Center for Health Statistics

Macdonald PD, Ross SR, Grant L, Young D (2003) Neonatal weight loss in breast and formula fed infants. Arch Dis Child Fetal Neonatal Ed 88: F472 - F476

Michels KB, Xue F (2006) Role of birthweight in the etiology of breast cancer. Int J Cancer 119: 2007-2025

Ogilvy-Stuart AL, Hands SJ, Adcock CJ, Holly JM, Matthews DR, MohamedAli V, Yudkin JS, Wilkinson AR, Dunger DB (1998) Insulin, insulin-like growth factor I (IGF-I), IGF-binding protein-1, growth hormone, and feeding in the newborn. J Clin Endocrinol Metab 83: 3550 - 3557

Park SK, Kang D, McGlynn KA, Garcia-Closas M, Kim Y, Yoo KY, Brinton LA (2008) Intrauterine environments and breast cancer risk: meta-analysis and systematic review. Breast Cancer Res 10: R8

Renehan AG, Zwahlen M, Minder C, O'Dwyer ST, Shalet SM, Egger M (2004) Insulin-like growth factor (IGF)-I, IGF binding protein-3, and cancer risk: systematic review and meta-regression analysis. Lancet 363: $1346-1353$

Rinaldi S, Peeters PH, Berrino F, Dossus L, Biessy C, Olsen A, Tjonneland A, Overvad K, Clavel-Chapelon F, Boutron-Ruault MC, Téhard B, Nagel G, Linseisen J, Boeing H, Lahmann PH, Trichopoulou A, Trichopoulos D, Koliva M, Palli D, Panico S, Tumino R, Sacerdote C, van Gils CH, van Noord P, Grobbee DE, Bueno-de-Mesquita HB, Gonzalez CA, Agudo A, Chirlaque MD, Barricarte A, Larrañaga N, Quiros JR, Bingham S, Khaw KT,
Key T, Allen NE, Lukanova A, Slimani N, Saracci R, Riboli E, Kaaks R (2006) IGF-I, IGFBP-3 and breast cancer risk in women: The European Prospective Investigation into Cancer and Nutrition (EPIC). Endocr Relat Cancer 13: 593-605

Russo J, Russo IH (1987) Development of the human mammary gland. In The Mammary Gland, Neville MC, Daniel CW (eds), pp 67-93. New York: Plenum Press

Savarese TM, Strohsnitter WC, Low HP, Liu Q, Baik I, Okulicz W, Chelmow DP, Lagiou P, Quesenberry PJ, Noller KL, Hsieh CC (2007) Correlation of umbilical cord blood hormones and growth factors with stem cell potential: implications for the prenatal origin of breast cancer hypothesis. Breast Cancer Res 9(3): R29

Skalkidou A, Petridou E, Papathoma E, Salvanos H, Trichopoulos D (2003) Growth velocity during the first postnatal week of life is linked to a spurt of IGF-I effect. Paediatr Perinat Epidemiol 17: 281-286

Stachenfeld NS, Keefe DL (2002) Estrogen effects on osmotic regulation of AVP and fluid balance. Am J Physiol Endocrinol Metab 283: E711 - E721

Stachenfeld NS, Taylor HS (2004) Effects of estrogen and progesterone administration on extracellular fluid. J Appl Physiol 96: 1011-1018

Strohsnitter WC, Savarese TM, Low HP, Chelmow DP, Lagiou P, Lambe M, Edmiston K, Liu Q, Baik I, Noller KL, Adami HO, Trichopoulos D, Hsieh CC (2008) Correlation of umbilical cord blood haematopoietic stem and progenitor cell levels with birth weight: implications for a prenatal influence on cancer risk. $B r$ J Cancer 98: 660-663

Tretli S (1989) Height and weight in relation to breast cancer morbidity and mortality. A prospective study of 570000 women in Norway. Int J Cancer 44: $23-30$

Trichopoulos D (1990) Hypothesis: does breast cancer originate in utero? Lancet 335: $939-940$

Trichopoulos D, Adami HO, Ekbom A, Hsieh CC, Lagiou P (2008) Early life events and conditions and breast cancer risk: from epidemiology to etiology. Int J Cancer 122: $481-485$

Trichopoulos D, Lagiou P, Adami HO (2005) Towards an integrated model for breast cancer etiology: the crucial role of the number of mammary tissue-specific stem cells. Breast Cancer Res 7: 13-17

World Cancer Research Fund/American Institute for Cancer Research (2007) Food, Nutrition, Physical Activity, and the Prevention of Cancer: a Global Perspective. Washington DC: AICR 